\title{
EI proyecto de vida como estrategia de libertad para el desarrollo estudiantil ante la crisis del COVID-19
}

The life project as a strategy of freedom for student development in the face of the COVID-19 crisis

O projeto de vida como estratégia de liberdade para o desenvolvimento do aluno diante da crise do COVID-19

Isidro Ignacio Alcívar Vera

isidro.alcivar@uleam.edu.ec Universidad Laica Eloy Alfaro de Manabí - Ecuador https://orcid.org/0000-0001-7243-8907

Félix Reinaldo Pastrán Calles felix.pastran@uleam.edu.ec Universidad Laica Eloy Alfaro de Manabí - Ecuador https://orcid.org/0000-0001-7046-8942

Gabriela Janeth Sión Saltos gabriela.sion@uleam.edu.ec Universidad Laica Eloy Alfaro de Manabí - Ecuador https://orcid.org/0000-0002-4299-706X

\section{RESUMEN}

La presente investigación tiene como objetivo valorar el proceso de construcción de los proyectos de vida como estrategia para el desarrollo estudiantil ante la crisis del Covid-19 en los estudiantes de la Universidad Laica Eloy Alfaro de Manabí, con el propósito de comprender sus objetivos, y otros, a través de esta estrategia de enseñanzaaprendizaje y así plasmar las metas corto, mediano y largo plazo. El trabajo se apoya en el enfoque cualitativo, de tipo descriptivo, cumpliendo con diferentes fases. La población fue de un total de 19 estudiantes en la Carrera de Turismo, Extensión Pedernales, durante el periodo académico 2020-1. En los resultados se evidencia la idea de la combinación de la asignatura Pensamiento Laico y Proyecto de Vida, para formar un ser libre para enfrentar la crisis del COVID-19 y que continúe con sus planes en el sector turístico. Se evidencia que desean culminar la carrera, seguir con estudios superiores y apoyar a su familia.

Palabras clave / Descriptores: Turismo, libertad, educación.

\begin{abstract}
The present research aims to assess the process of construction of life projects as a strategy for student development in the face of the Covid-19 crisis in students of the Universidad Laica Eloy Alfaro de Manabí, in order to understand objectives, and others, through this teaching-learning strategy to achieve short-, medium- or long-term goals. The qualitative approach, of a descriptive type, complying with different phases. The population was a total of 19 students in the Tourism Career, Pedernales Extension, during the 2020-1 academic period. The results show the idea of combining the Secular Thinking and Life Project course, to form a free being to face the COVID-19 crisis and continue with its plans in the tourism sector. It is evident that they want to complete their degree, continue with higher education and support their family.
\end{abstract}

Keywords: Tourism, freedom, education.

\section{RESUMO}

A presente pesquisa tem como objetivo avaliar o processo de construção de projetos de vida como estratégia de desenvolvimento discente diante da crise Covid-19 em alunos da Universidade Laica Eloy Alfaro de Manabí, a fim de compreender seus objetivos, e outros, por meio de essa estratégia de ensino-aprendizagem e, assim, captar os objetivos de curto, médio e longo prazo. O trabalho baseia-se numa abordagem qualitativa, descritiva, cumprindo diferentes fases. A população totalizou 19 alunos da Carreira em Turismo, Extensão Pedernales, durante o período letivo 2020-1. Os resultados mostram a ideia de unir o curso de Pensamento Secular e Projeto de Vida, para formar um ser livre para 
enfrentar a crise do COVID-19 e dar continuidade aos seus planos no setor de turismo. É evidente que desejam terminar a licenciatura, continuar o ensino superior e sustentar a família.

Palavras chave: Tourism, freedom, education.

\section{INTRODUCCIÓN}

El proyecto de vida permite plasmar las metas corto, mediano o largo plazo, en distintos ámbitos de la vida; todo ello, se materializa en un documento de tipo texto, mapa conceptual, tabla o compilación de imágenes donde se delimitarán las actividades y estrategias que se desean realizar para alcanzar los objetivos fijados y desde las instituciones educativas, permite que el proyecto de vida se oriente hacia la vocación del estudiante, el deseo familiar, profesional y social.

Abraham Maslow, en su teoría de las necesidades define la autorrealización como el mecanismo interno que nos lleva a enfocar nuestros esfuerzos hacia un objetivo determinado, de manera organizada o no, con la finalidad de dirigirnos hacia el crecimiento personal o profesional, tomando en cuenta que cada persona tiene sueños y aspiraciones distintas para sentirse "realizado" (Maslow, 1991). En ese sentido, tener un propósito de vida, otorga un mayor sentido de competencia personal (González, 2016), como resultado de la planificación estratégica en los distintos aspectos de la vida, así pues, se establecen pasos para llegar a lograr metas y cumplir objetivos con éxito.

Sin embargo, también es importante tomar en cuenta los factores externos que pueden alterar el plan inicial, para estar listos a actuar e implementar un plan de contingencia para hacer frente a imprevistos que se puedan presentar en el camino. En ese sentido, se debe de realizar una introspección para identificar las fortalezas y debilidades del individuo que realizará el proyecto, con la finalidad de aprovechar las potencialidades de manera consciente, comprendiendo y aceptando las debilidades que posee.

Por tales motivos, el autoconocimiento es el eje principal del bienestar psicológico de una persona, en este sentido, Corbin (2020) señala que cuando las personas se conocen bien, son capaces de identificar de forma clara los logros que desean alcanzar tomando en cuenta aspectos cotidianos, así como proyectos de gran importancia, así como saben gestionar mejor sus emociones, incluso en los momentos de mayor dificultad, incluyendo situaciones críticas, pero aun así, posee armonía en su interior.

Para elaborar un proyecto de vida, se debe analizar y comprender las siguientes tres preguntas: ¿Quién soy? ¿Cuál es mi situación actual? y ¿Hacia dónde me dirijo?, con la finalidad de hacer un análisis del Ser, de la realidad y la función del sujeto actual, y la visión que posee para su desarrollo humano. En ese contexto, la investigación tiene como objetivo, Valorar el proceso de construcción de los proyectos de vida como estrategia para el desarrollo estudiantil ante la crisis del Covid-19 en los estudiantes de la Universidad Laica Eloy Alfaro de Manabí, con el propósito de comprender sus necesidades, querencias, sentimientos, anhelos, sueños, deseos, objetivos, y otros.

\section{PROCEDIMIENTOS METODOLOGICOS}

El trabajo posee un enfoque cualitativo, que en palabras de Hernández et al., (2014, p.358) se entiende como "comprender los fenómenos, explorándolos desde la perspectiva de los participantes en un ambiente natural y en relación con su contexto, ....profundizando en sus puntos de vista, interpretaciones y significados", ya que los proyectos de vida presentados por los estudiantes se realizaron en conjunto con la asesoría de los docentes, cumpliendo con diferentes fases, iniciando con el acompañamiento durante aproximadamente dos meses, en los que se mantuvieron tutorías académicas de forma periódica conforme a las necesidades y dudas de los participantes, con el apoyo de la investigación acción, la cual según (Martinez, 1996) define que: 
La IA es un trabajo fundamentalmente educativo orientado hacia la acción. La educación se entiende aquí no como trasmisión didáctica de conocimientos, sino como el aprender por IA búsqueda y la investigación de nuestras realidades más cercanas, y con el fin de solucionar un problema, o varios, y reorientar nuestra acción y nuestra vida (p. 223)

En este caso, la búsqueda consiste en la reflexión de la realidad de cada estudiante, y no como una mera trasmisión de conocimiento, aprendiendo a través del diagnóstico, la teoría y las experiencias, en camino que se recorre y el futuro que se pretende transitar, buscando la calidad de vida y el logro de los sueños planificados.

La población es finita (Belkis, 2014) y está conformada por 19 estudiantes de la Carrera de Turismo, en la Universidad Laica Eloy Alfaro de Manabí (ULEAM), Extensión Pedernales, durante el periodo académico 2020 (1). Es preciso señalar el empleo de fuentes primarias y secundarias, esta última ya que es "un proceso basado en la búsqueda, recuperación, análisis, crítica e interpretación de datos secundarios, es decir, los obtenidos y registrados por otros investigadores en fuentes documentales: impresas, audiovisuales o electrónicas" (Arias, 2012, p.27) para construir un marco conceptual relacionado con la temática objeto de estudio.

Se procedió a transcribir la información protocolar, se dividieron los contenidos en porciones o unidades temáticas que expresan ideas centrales, se definió la categorización, la cual según (Martínez, 2004) consiste en: "clasificar, conceptualizar o codificar mediante un término o expresión breve que sean claros e inequívocos (categoría descriptiva), el contenido o idea central de cada unidad temática" (p. 268), identificando las siguientes en esta investigación: proyecto de vida, libertad, desarrollo estudiantil y covid-19. La estructuración ha sido de tipo descripción normal y endógena (Martínez, 2004)

La validez fue de tipo interna, externa, con fiabilidad y objetividad (Paz, 2000) y finalmente, culminados los proyectos se organizó una feria virtual a la que se tituló "1ra Feria virtual de presentación de proyectos de vida", en la que los estudiantes interactuaron con asistentes y expusieron al público todos sus deseos, sueños, anhelos, metas, etc., que se han planteado cumplir en el corto, mediano y largo plazo.

\section{RESULTADOS Y DISCUSIÓN}

La Universidad Laica Eloy Alfaro de Manabí, como Institución de Educación Superior (IES), se identifica con el pensamiento laico, por lo que estudiantes en formación cursan en todas las carreras la siguiente asignatura: "Pensamiento laico y proyecto de vida", de una manera transversal, con la finalidad de reflexionar y comprender el génesis del pensamiento laico y su incidencia en los contextos sociales, políticos y educativos del Ecuador; así como la trascendencia del pensamiento Alfarista en la vida de los ecuatorianos desde el triunfo de la revolución liberal y su pensamiento libertario.

La idea de la combinación del laicismo con el proyecto de vida se fundamenta en la libertad que esta corriente ideológica le da al ser humano para pensar, identificarse, sentirse, etc., alejado de cualquier influencia religiosa que pudiera limitar, dogmatizar o estandarizar la visión de cada sujeto y por ende el desarrollo o el establecimiento de caminos a seguir para cumplir sus objetivos de vida plasmados en sus proyectos. Al respecto de esta afirmación es pertinente señalar las palabras de Salazar et al., (2015, p.32), cuando menciona que "la laicidad, en efecto, promueve la emancipación del poder civil ante el poder religioso y, en algunos contextos, ello ha implicado el debilitamiento y sometimiento del segundo ante el primero".

Esta idea de libertad de ser, respaldada en el laicismo, se ve plasmada en el Estatuto de la Uleam, y en su Modelo Educativo, el primero sostiene en el Art. 6, numeral 7, dentro de los fines de la institución: Practicar, difundir y defender el laicismo, como principio de la educación ecuatoriana 
(Estatuto Uleam, 2019, p.7). Mientras que el segundo, expone: formar a una persona reflexiva, crítica, autocrítica, solidaria, afectuosa, leal, dueña de sus acciones, autónoma, es decir, libre (Reyes, 2016, p.2). Son precisamente estas ideas de autonomía y libertad, las que los estudiantes han escrito en sus proyectos de vida, convirtiéndolos en una ruta a seguir, en momentos tan difíciles como los actuales, donde se destaca la crisis del COVID-19.

En ese mismo orden de ideas, refiriéndonos al sílabo y programa analítico de la asignatura, ambos declaran que el estudiante debe comprender la relevancia del liberalismo en la educación desde el pensamiento radical de Alfaro relacionándolo con los tiempos actuales, por ello, es coherente citar también lo que menciona el estatuto institucional en su Art. 8, donde se hace énfasis en el patrono de la institución don Eloy Alfaro Delgado (1842-1912), quien practicó el laicismo como principio básico de su existencia, entendido, precisamente como un constructo de las condiciones políticas, jurídicas y sociales idóneas para el pleno desenvolvimiento de la libertad de conciencia (Estatuto Uleam, 2019, p.7). Lo que se pretende que el estudiante direccione sus esfuerzos para alcanzar sus ideales, cumplir sus sueños, lograr sus metas, todo esto conjugado en un escenario de total libertad de pensamiento.

En ese sentido, desde lo curricular, la asignatura no pretende direccionar al estudiante y mucho menos, dogmatizar ideas, por lo contrario, tiene como propósito crear el proyecto de vida desde la libertad del hombre, fundamentado en pensamientos lógicos y claros, de tal forma que pueda ordenar, plantear y cumplir en el tiempo que considere prudente, tomando en cuenta su realidad, recursos, formación, oportunidades laborales, becas, etc.

Cabe destacar que el docente debe ser empático y a través de distintas estrategias de enseñanza-aprendizaje, como: talleres, tutorías, consultas en la web, círculos literarios, este último concebido como "grupos de discusión, por lo general pequeños, que se forman teniendo en mente leer y hablar en torno a una historia (Daniels, 1994, citado en Villafuerte et al., 2017, p.58), cuya práctica es tradicionalmente presencial, pero que ante la crisis del COVID-19, se desarrollaron en escenarios virtuales, con el fin de incentivar nuevas ideas entre los estudiantes.

Como producto de la asignatura, al culminar el semestre los estudiantes tienen conocimiento epistemológico del laicismo y el proceso que Alfaro llevó sobre sus hombros para instaurar el laicismo en el país; junto a las ideas libertarias que sirvieron de apoyó en la construcción de los proyectos de vida.

En la actualidad, la actividad turística ha sido uno de los sectores más golpeados por la crisis del COVID-19, trayendo consigo la cancelación de viajes, restricciones fronterizas, aerolíneas y hoteles en banca rota, trabajadores del sector sin empleo, conflictos políticos en distintas escalas, y hasta una posible eliminación del Ministerio de Turismo, es decir, existen consecuencias importantes que ha tenido una repercusión en el quehacer de este sector (Abella, 2020, p.22; Alcívar, 2020, p.10).

Razón por la cual, es notorio preguntar ¿Qué efectos genera el COVID-19 en los estudiantes de turismo?, debido que es evidente que este virus también afectó su realidad y los movilizó de su zona de confort, trasladándolos a un escenario estrictamente virtual; el cual, no es propicio para desarrollar el proceso de enseñanza-aprendizaje con éxito, por ser la enseñanza turística de esencia racionalista, empírico, vivencial e interpretativo.

No obstante, se debe reconocer que el turismo ha tenido un proceso evolutivo (Acerenza, 2006) y significativo hasta llegar a una amplia comercialización de productos, servicios y destinos en formato virtual, un ejemplo de ello es: Online Travel Agency (OTA), los Sistemas de Distribución Global (GDS), y algunos buscadores especializados, pero lo anterior, no justifica que la formación académica en el área de turismo sea sometida a la predominancia de parámetros de virtualización.

Es común escuchar a las personas hablar de proyectos, cuando tienen ideas que hipotéticamente podrían aplicar en su vida, no obstante, cuando de manejan proyectos, es necesario 
establecer una serie de mecanismos, fases y procesos que permitan cumplir con los objetivos planteados en respuesta a las necesidades o problemas. En ese sentido, es pertinente mencionar que el proyecto de vida como una estrategia de enseñanza-aprendizaje se ha transformado de lo tradicional, con características de presencialidad, hacia la virtualidad. Esta afirmación coincide con lo planteado por Morales y Trueba (2011), al manifestar el concepto de proyecto

...engloba una disparidad semántica que se extiende en todos los ámbitos de la actividad profesional y no profesional: proyecto de ley, proyecto de vida, gestión de la empresa por proyectos, proyectos de ingeniería, etc. Por lo general la utilización de la palabra proyecto está asociada a la abstracción mental del plan necesario para ejecutar una acción concreta. (p.338)

En tal virtud, es preciso señalar desde la perspectiva de la psicología-social, el proyecto de vida "es la estructura que expresa la apertura de la persona hacia el dominio del futuro, en sus direcciones esenciales y en las áreas críticas que requieren de decisiones vitales" (D’angelo, 2003, p.3), es decir, es aquello que pretende que el educando pueda manejar, visionando su futuro, y aun cuando existan momentos que pudieran retrasar el cumplimiento de sus objetivos, tengan una de ruta que recuerde hacia donde transitar.

Asimismo, se justifica el proyecto de vida por su metodología activa para contribuir al desarrollo de competencias, Pimienta (2012, p.132), manifiesta que los proyectos son una "metodología integradora que plantea la inmersión del estudiante en una situación o una problemática real que requiere solución o comprobación. Se caracteriza por aplicar de manera práctica una propuesta que permite solucionar un problema real desde diversas áreas de conocimiento...”. En ese contexto, muchos de los jóvenes que llegan a los primeros semestres de la educación universitaria se encuentran aún en el proceso de esclarecer sus ideas, objetivos, deseos, anhelos, etc., por lo que se convierte en una estrategia pertinente en el diálogo entre los educandos, donde pueden compartir e intercambiar opiniones y posturas relacionadas con su futuro próximo.

Solicitar un proyecto de vida a jóvenes entre 16 y 18 años de edad es complejo debido al contexto, la influencia de los padres, y algún otro factor externo, por ello, es recomendable manejar los tiempos y espacios, para direccionar las ideas, ya que: "si el joven de hoy no tiene claro hacia dónde va, cualquier camino le sirve" (Murillo, 2014, p.40). Enmarcados en esa afirmación, la construcción del proyecto de vida le permite al estudiante

...articular la identidad personal social en las perspectivas de su dinámica temporal y posibilidades de desarrollo futuro. Se comprende, entonces, como un sistema principal de la persona en su dimensionalidad esencial de la vida. Es un modelo ideal sobre lo que el individuo espera o quiere ser y hacer, que toma forma concreta en la disposición real y sus posibilidades internas y externas de lograrlo, definiendo su relación hacia el mundo y hacia sí mismo, su razón de ser como individuo en un contexto y tipo de sociedad determinada. (Hernández, 2000, p.272)

En similitud de ideas, autores como Castañeda (2001), han sabido manifestar que un joven que prepara su plan de vida, se prepara para triunfar, difícilmente fracasará, y probablemente dejará huella profunda en el mundo. Este autor, sostiene además que este proyecto de vida no es una fórmula para vivir, sino un componente que apoya al estudiante a dar sentido a su existencia, una dirección a dónde quiere llegar y que tiene un significado específico para él, y con la orientación del docente, específicamente ante la situación actual de la crisis sanitaria, es indispensable orientar esos objetivos que el participante pretende alcanzar.

Existen diversas técnicas de enseñanza-aprendizaje como: preguntas exploratorias, cuadros sinópticos, mapas conceptuales diagramas, ensayos, etc. (Parra, 2003; Pimienta, 2012), de la cuales el proyecto de vida se nutre como estrategia que acepta la subjetividad de cada individuo, conforme con sus aspiraciones, disposición de recursos, entre otros factores que inciden en el logro de su plan de vida. 
Desde la postura de los docentes, la construcción del proyecto de vida se convirtió también en una oportunidad de conocer de cerca las realidades que viven los estudiantes, sus objetivos personales, los cuales no siempre están relacionados con fines académicos, sino también personales, empresariales, familiares, deportivos, sentimentales, etc., por lo que el profesor se compromete para direccionar el cumplimiento de estos a través de la ejecución de la práctica, fundamentada en los contenidos teóricos, relacionado con el aspecto afectivo, cognitivo y conductual en cada tema desarrollado (Cornejo, 2015, p.28), por lo que el docente analiza y comprende las interacciones que se generan en el escenario docente-estudiante y así enriquecer las futuras estrategias de enseñanza.

Así pues, en un primer momento (Ver tabla 1), se exponen aspectos relacionados a las edades de los participantes, sexo y nivel académico (semestre).

Tabla 1: Aspectos generales de los participantes

\begin{tabular}{|r|l|l|}
\hline \multicolumn{1}{|c|}{ Grupo etario } & \multicolumn{1}{|c|}{ Sexo } & \multicolumn{1}{c|}{ Nivel (semestre) } \\
\hline $\begin{array}{l}\text { Los rangos de edad de los participantes } \\
\text { oscilaron entre 17 y } 23\end{array}$ & 16 mujeres & 2do semestre \\
\cline { 2 - 3 } & 3 hombres & 2do semestre \\
\hline Total & 19 & \\
\hline
\end{tabular}

Fuente: Elaborado por los autores.

En un segundo momento y con estos aspectos puestos a conocimiento, se presenta el proceso con el que se trabajó el desarrollo de los proyectos de vida de los estudiantes.

El proceso partió por socializar en clases la temática relacionada al proyecto de vida, donde se esbozaron ideas básicas afines a este, así como la bibliografía existente sobre el asunto y que se utilizará en la asignatura, de tal forma que el estudiante puede ubicarse conceptualmente en lo que se desea realizar en la asignatura. Dentro de esa misma clase, se dejó un espacio de tiempo prudente al finalizar, donde cada uno de los estudiantes expuso de manera "piloto" sus ideas, objetivos, sueños y similares, que les gustaría alcanzar en determinados plazos de tiempo. Esta primera interacción, abrió todo un dialogo, puesto que mientras alguien exponía sus ideas, algunos decían coincidir en la misma meta, enriqueciendo así el espacio de tiempo destinado para esta primera actividad.

En la siguiente clase, se socializaron los ámbitos sobre los que habría que desarrollar los proyectos de vida, en tal sentido, se propuso al estudiante trabajar desde las siguientes perspectivas: personal, escolar, familiar y laboral, sin que estos fueran los únicos y dejando la puerta abierta para abordar cualquier otra arista conforme a los objetivos del educando.

Es importante comentar, que para cada ámbito se establecieron parámetros: objetivo (¿Qué deseo?), tiempo (¿En cuánto tiempo lo lograré?), estrategias (¿Cómo lo voy a hacer?) y apoyos externos (¿En quién me puedo apoyar para lograrlo?). en ese sentido, a continuación, se presenta la tabla 2, que demuestra el esquema para desarrolla el proyecto de vida.

Tabla 2: Esquema para desarrollar el proyecto de vida

\begin{tabular}{|l|l|l|l|l|}
\hline ÁMBITO & OBJETIVO & $\begin{array}{l}\text { TIEMPO } \\
\text { ¿En cuánto } \\
\text { tiempo lo } \\
\text { lograré }\end{array}$ & $\begin{array}{l}\text { ESTRATEGIAS } \\
\text { ¿Cómo lo voy a } \\
\text { hacer? }\end{array}$ & $\begin{array}{l}\text { APOYOS } \\
\text { EXTERNOS } \\
\text { ¿En quién me } \\
\text { puedo apoyar } \\
\text { para lograrlo? }\end{array}$ \\
\hline Personal & & & & \\
\hline Escolar & & & & \\
\hline
\end{tabular}




\begin{tabular}{|l|l|l|l|l|}
\hline Familiar & & & & \\
\hline Laboral & & & & \\
\hline
\end{tabular}

Fuente: Elaborado por los autores.

Cómo se observa en la tabla anterior, la idea es que el estudiante plantee sus objetivos dentro de los diferentes ámbitos y que uno de ellos se logre, es consecuencia, es asertiva la estrategia en estudio para lograr tal fin.

Posteriormente, se manejó el desarrollo de los proyectos a través de tutorías personalizadas, cada estudiante posee sus particularidades, por ello requiere de asesoría y acompañamiento personal para diagnosticar, planificar, programar y llevar a la práctica el proyecto. Un aspecto importante en el que se hizo énfasis en las tutorías fue el tiempo, puesto que este no debe ser visto como control, u obligación; aunque es importante, el tiempo es un elemento que debe ser comprendido desde la realidad de cada ser, y el ritmo lo establece esa realidad, por lo que la planificación, debe ser consciente y real al momento de estimar un tiempo para una meta.

De esta manera, el proyecto de vida identifica de manera clara lo que se desea lograr, resaltando en todo momento el principio de libertad del ser y del educando, de la mano con el apoyo familiar, bancario, amistad, estatal, ONG, becas, entre otros.

Luego del acompañamiento con las tutorías, en el lapso de un mes y medio, se presentaron los proyectos como prueba piloto, donde los estudiantes expusieron sus trabajos a los docentes, donde se generó un feedback, es decir, el intercambio de ideas, sugerencias y algunas correcciones principalmente al material (presentaciones en formato de PowerPoint) que se utilizaría para la posterior exposición formal. Una vez finalizados los trabajos y las presentaciones, se procedió a desarrollar una invitación (ver gráfico 1), en la que se convocó a la comunidad universitaria de la Extensión Pedernales a participar de una feria virtual en la que los estudiantes expondrían sus trabajos finales.

Gráfico 1. Invitación a la feria virtual de proyectos de vida, de los estudiantes de la carrera de Turismo en la ULEAM - Extensión Pedernales.

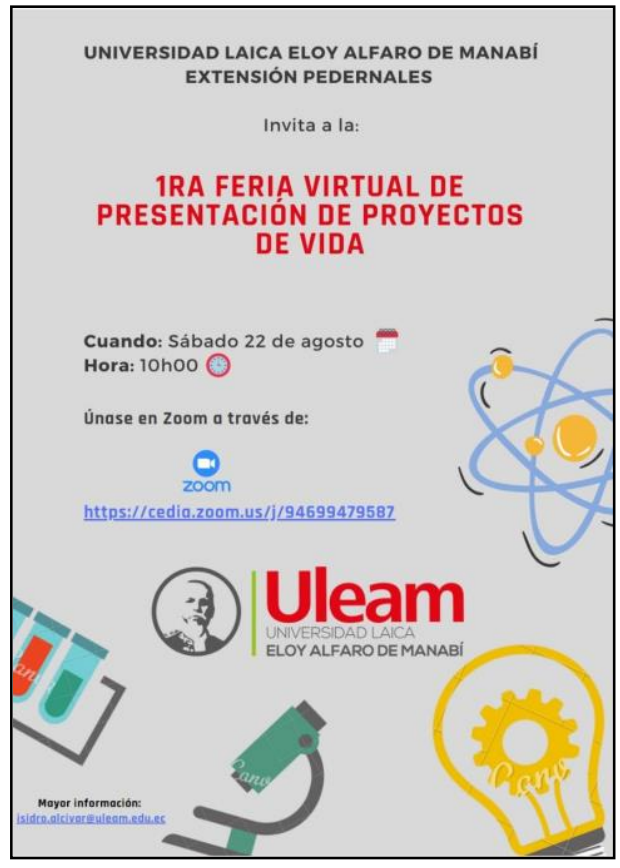

Fuente: Elaborado por los autores.

La feria tuvo presencia de docentes de la Extensión, estudiantes de las carreras de Agropecuaria y Administración de Empresas, familiares de los expositores y algunas personas 
pertenecientes a la sociedad civil del cantón Pedernales, a través de la plataforma ZOOM, por lo que fue novedoso, ya que ha sido la primera vez que se emplea por medio de la virtualidad y no como se acostumbraba ejecutando de manera tradicional, es decir, presencial, para evitar el incremento de contagios por COVID-19 y precautelar la salud de los actores universitarios. Posteriormente, el vídeo de la feria fue cargado a la red social YouTube y se encuentra disponible en el siguiente enlace: https://youtu.be/RRiJ863OnP4.

Después de la presentación de los trabajos, en la clase siguiente se dialogó sobre la experiencia que le representó al estudiante haber desarrollado este tipo de actividad y haberlo compartido con otras personas, obteniendo comentarios como "fue una experiencia significativa", "me ayudó a aclarar mis ideas", "pude visionar mi futuro", entre otros. En el siguiente gráfico, se expone de manera lógica todo el proceso llevado a cabo para el desarrollo de los proyectos de vida.

Gráfico 2. Secuencia lógica de trabajo

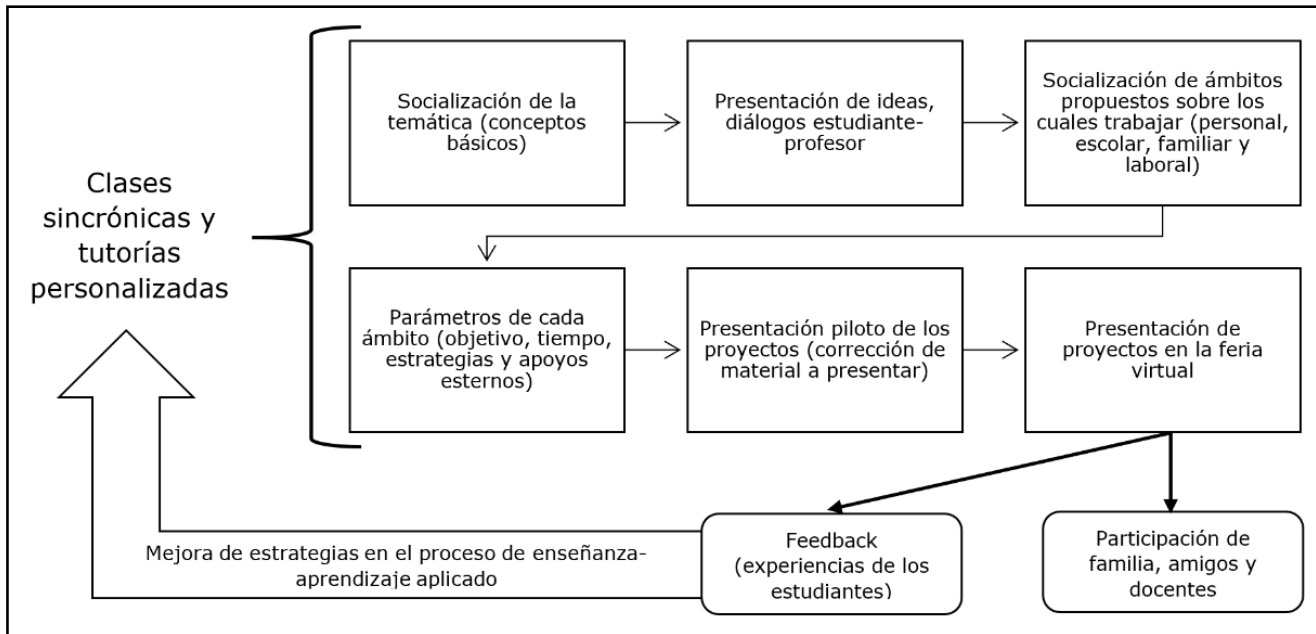

Fuente: Elaborado por los autores.

Después de cumplir con todo este proceso, se procedió a revisar cada uno de los proyectos de vida de los estudiantes participantes, y extraer las principales ideas propuestas en los cuatro ámbitos, pero también en cualquier otro que ellos quisieran trabajar, en ese sentido, se presenta la siguiente tabla, para visualizar los objetivos, sueños y anhelos de los educandos.

Tabla 3: Principales objetivos de los estudiantes

\begin{tabular}{|c|l|l|l|l|l|}
\hline Sexo & \multicolumn{1}{|c|}{ Personal } & \multicolumn{1}{c|}{ Estudios } & \multicolumn{1}{c|}{ Familia } & \multicolumn{1}{c|}{ Trabajo } & Otros ámbitos \\
\hline F & Ser profesional & $\begin{array}{l}\text { Estudiar una } \\
\text { maestría }\end{array}$ & Sabiduría y valores & Buena economía & N/A \\
\hline F & $\begin{array}{l}\text { Empoderamiento } \\
\text { femenino }\end{array}$ & $\begin{array}{l}\text { Graduarse de } \\
\text { la Universidad }\end{array}$ & $\begin{array}{l}\text { Ser una madre } \\
\text { ejemplar }\end{array}$ & $\begin{array}{l}\text { Tener una mejor } \\
\text { economía }\end{array}$ & N/A \\
\hline F & Tener un mariachi & $\begin{array}{l}\text { Estudiar otra } \\
\text { carrera }\end{array}$ & $\begin{array}{l}\text { Educación en } \\
\text { valores }\end{array}$ & $\begin{array}{l}\text { Tener una tienda de } \\
\text { calzado }\end{array}$ & N/A \\
\hline F & Independizarse & $\begin{array}{l}\text { Graduarse de } \\
\text { la Universidad }\end{array}$ & Formar una familia & $\begin{array}{l}\text { Tener un trabajo } \\
\text { estable }\end{array}$ & N/A \\
\hline F & $\begin{array}{l}\text { Ser una persona de } \\
\text { bien }\end{array}$ & $\begin{array}{l}\text { Ser buena } \\
\text { estudiante }\end{array}$ & Cuidar de sus padres & $\begin{array}{l}\text { Conseguir un } \\
\text { trabajo en turismo }\end{array}$ & $\begin{array}{l}\text { Deportivo: ser } \\
\text { futbolista } \\
\text { profesional }\end{array}$ \\
\hline F & Visitar Italia & $\begin{array}{l}\text { Estudiar una } \\
\text { maestría en } \\
\text { turismo }\end{array}$ & $\begin{array}{l}\text { Reconstruir lazos } \\
\text { familiares }\end{array}$ & Ser educadora & $\begin{array}{l}\text { Espiritual: } \\
\text { aprender yoga }\end{array}$ \\
\hline F & Viajar por Ecuador & $\begin{array}{l}\text { Culminar la } \\
\text { Universidad }\end{array}$ & $\begin{array}{l}\text { Tener una familia } \\
\text { unida }\end{array}$ & $\begin{array}{l}\text { Crear una empresa } \\
\text { de turismo }\end{array}$ & N/A \\
\hline
\end{tabular}




\begin{tabular}{|c|c|c|c|c|c|}
\hline $\mathrm{F}$ & Viajar & $\begin{array}{l}\text { Culminar la } \\
\text { Universidad }\end{array}$ & Formar una familia & Tener un empleo & N/A \\
\hline $\mathrm{F}$ & $\begin{array}{l}\text { Viajar por Ecuador } \\
\text { y Dubái }\end{array}$ & $\begin{array}{l}\text { Estudiar un } \\
\text { doctorado }\end{array}$ & Formar una familia & Trabajar en turismo & $\begin{array}{l}\text { Empresarial: } \\
\text { Crear una } \\
\text { empresa } \\
\text { agroturística }\end{array}$ \\
\hline $\mathrm{F}$ & $\begin{array}{l}\text { Auto realizarse } \\
\text { como mujer }\end{array}$ & $\begin{array}{l}\text { Culminar la } \\
\text { Universidad }\end{array}$ & Ser una buena hija & $\begin{array}{l}\text { Ser una buena } \\
\text { profesional }\end{array}$ & N/A \\
\hline $\mathrm{F}$ & $\begin{array}{l}\text { Viajar, conocer el } \\
\text { mundo }\end{array}$ & $\begin{array}{l}\text { Estudiar un } \\
\text { doctorado }\end{array}$ & Apoyar a la familia & $\begin{array}{l}\text { Crear una empresa } \\
\text { de turismo }\end{array}$ & N/A \\
\hline $\mathrm{F}$ & Viajar a otros países & $\begin{array}{l}\text { Participar en } \\
\text { congresos }\end{array}$ & Apoyar a la familia & $\begin{array}{l}\text { Montar una } \\
\text { empresa de } \\
\text { manualidades }\end{array}$ & N/A \\
\hline $\mathrm{F}$ & Crecer en valores & $\begin{array}{l}\text { Graduarse de } \\
\text { la Universidad }\end{array}$ & Apoyar a sus padres & $\begin{array}{l}\text { Ejercer su } \\
\text { formación } \\
\text { profesional } \\
\end{array}$ & N/A \\
\hline $\mathrm{M}$ & $\begin{array}{l}\text { Apoyar el } \\
\text { crecimiento turístico } \\
\text { comunitario }\end{array}$ & $\begin{array}{l}\text { Estudiar un } \\
\text { doctorado }\end{array}$ & Formar una familia & $\begin{array}{l}\text { Tener una empresa } \\
\text { hotelera }\end{array}$ & N/A \\
\hline $\mathrm{M}$ & $\begin{array}{l}\text { Ser útil y } \\
\text { competente en la } \\
\text { sociedad }\end{array}$ & $\begin{array}{l}\text { Continuar } \\
\text { estudiando }\end{array}$ & Apoyar a sus padres & $\begin{array}{l}\text { Mejorar sus } \\
\text { ingresos }\end{array}$ & N/A \\
\hline $\mathrm{F}$ & Conocer Santorini & $\begin{array}{l}\text { Graduarse de } \\
\text { la Universidad }\end{array}$ & $\begin{array}{l}\text { Tener una vida } \\
\text { estable para sus } \\
\text { hijos } \\
\end{array}$ & $\begin{array}{l}\text { Crear una empresa } \\
\text { familiar }\end{array}$ & N/A \\
\hline $\mathrm{F}$ & Independizarse & $\begin{array}{l}\text { Graduarse de } \\
\text { la Universidad }\end{array}$ & $\begin{array}{l}\text { Apoyar } \\
\text { económicamente a } \\
\text { sus padres }\end{array}$ & $\begin{array}{l}\text { Ejercer su } \\
\text { formación } \\
\text { profesional }\end{array}$ & N/A \\
\hline $\mathrm{F}$ & Viajar a otros países & $\begin{array}{l}\text { Graduarse de } \\
\text { la Universidad }\end{array}$ & $\begin{array}{l}\text { Apoyar } \\
\text { económicamente a } \\
\text { sus padres }\end{array}$ & Trabajar en turismo & $\begin{array}{l}\text { Empresarial: } \\
\text { crear una } \\
\text { empresa } \\
\text { familiar }\end{array}$ \\
\hline $\mathrm{F}$ & Viajar a otros países & $\begin{array}{l}\text { Estudiar } \\
\text { gastronomía y } \\
\text { repostería }\end{array}$ & Colaborar en casa & $\begin{array}{l}\text { Administrar un } \\
\text { hotel }\end{array}$ & N/A \\
\hline
\end{tabular}

Fuente: Elaborado por los autores.

Al respecto de la tabla 3 , se observan algunas coincidencias, las féminas muestran una conducta bastante ligada a la autorrealización, empoderamiento e independencia, una situación coherente con las tendencias actuales en cuanto al feminismo, visto de una perspectiva sana y que debe ser apoyada. Por su parte, los hombres exteriorizan más bien deseos de viajar y ser útiles dentro de sus competencias profesionales y prácticas.

En cuanto a los estudios, es claro que tanto hombres como mujeres anhelan culminar sus carreras universitarias, sin embargo, se aprecia que muchos de los participantes pretenden continuar con la formación de cuarto nivel, de ahí que varios hayan manifestado que desean estudiar maestrías y doctorados. Sobre el ámbito familiar, hay dos tendencias bien marcadas, por una parte, un grupo desea apoyar a su familia, es decir, a sus padres y hermanos, mientras que otro grupo, desea tener su propia familia, de tal forma desean tener una vida estable.

Otro elemento importante dentro del futuro de los estudiantes es el trabajo, por ello se aprecia que todos coinciden en desarrollar algún tipo de actividad laboral, algunos desean trabajar en turismo y así ejercer su profesión, otros crear sus propias empresas ligadas al sector turísticos, entre otras actividades, el fin común, es tener una economía estable.

En la opción de "otros ámbitos", es decir algún otro campo de acción sobre el cual los estudiantes propusieron sus proyectos de vida, se puede observar que dos de ellos coinciden en objetivos empresariales, al crear una empresa familiar y otro una empresa agroturística. Así mismo, 
en el ámbito deportivo una estudiante desea ser futbolista profesional, mientras que, en lo espiritual, la estudiante desea aprender yoga.

Todas estas coincidencias y diferencias conjugadas han enriquecido este proceso de enseñanza-aprendizaje, permitiendo que los estudiantes exteriorizar sus pretensiones y establecer mecanismos que les permitan cumplirlas. Mientras que, visto desde la óptica de los docentes, se ha corroborado el desarrollo del proyecto de vida como una estrategia pertinente que aporta al crecimiento del estudiante, el intercambio de ideas y por supuesto, al proceso de enseñanza.

\section{CONCLUSIÓN}

A lo largo del texto se pudo observar la importancia del proyecto de vida como estrategia de libertad para el desarrollo estudiantil ante la crisis del covid-19, ya que a pesar de la realidad social, económica y de salud que atraviesa el mundo, el proceso educativo y las IES siguen apoyando a las futuras generaciones, en el caso específico de esta universidad, se valora el proceso de construcción de los proyectos de vida como estrategia para el desarrollo estudiantil ante la crisis del Covid-19, concretamente en los estudiantes de la carrera de turismo, por ser ellos los encargados a mediano plazo de prestar el servicio a los turistas.

Desde lo metodológico, se presentan algunos limites desde lo cualitativo, lo cual se recomienda para otros estudios de igual índole, relacionar el enfoque cualitativo con el cuantitativo con el propósito de comprender mejor el tema investigativo, desde otro enfoque. De igual manera, se reconoce que la fidelidad y objetividad de los datos son en cierta parte subjetivos, por lo que se debe ampliar la población para nuevos estudios y así confrontar los resultados. Otro factor externo se considera la realidad económica de cada estudiante, lo cual limita de manera directa sus sueños por ser un elemento que entorpece su desarrollo en la sociedad, para ello, se recomienda hacer énfasis en el liderazgo, autoestima, planificación y valores como persistencia para lograr los objetivos de vida.

En ese sentido, se hace la salvedad de la realidad virtual de los contenidos y práctica pero es comprendida y aceptada por el cuidado de los universitarios, así pues, la totalidad de los proyectos de vida poseen continuidad en sus ideas, sueños y esperanzas, es decir, la pandemia no ha sido un obstáculo o limitante para seguir en el proceso formativo, por lo contrario, cada estudiante es consciente del contexto, se protege como individuo y protege al colectivo, sin perder el horizonte de sus metas, reafirmando en este espacio académico el camino hacia la titulación, la estabilidad familiar, económica, visto desde la libertad y los principios humanos que emite la Universidad Laica Eloy Alfaro de Manabí.

En conclusión, se reconoce como contribución científica que los estudiantes tienen un nivel importante de resiliencia, el cual le permite seguir visualizando su proyecto de vida, el cual esta para sostener al participante dentro de la dinámica social propia del siglo XXI y se recomienda para futuros proyectos investigativos reunirlos por áreas, por tendencia de la recepción del conocimiento, y garantizar el desarrollo del aprendizaje desde cada individualidad.

\section{REFERENCIAS}

Abella, S. (2020). Situación del sector turístico y de la crisis. In F. Bauzá \& F. Melgosa (Eds.), Turimso post COVID-

19. El turismo después de la pandemia global: análisis, perspectivas y vías de recuperación (1st ed., p. 270).

Asociación Española de Expertos Cientítificos en Turismo. https://aecit.org/uploads/public/DOCUMENTO.covid-19 y turismo.pdf

Academia de tutorías. (S.F.). Taller de estrategia de aprendizaje. Universidad Tecnológica de Jalisco. http://www.utj.edu.mx/tutorias/archivos/Anexos_TIC.pdf

Acerenza, M. Á. (2006). Conceptualización, Origen y Evolución del Turismo (1st ed.). Editorial TRILLAS. https://doi.org/380.1459104'A545c 
Alcívar, I. (2020, June 5). Estudiar turismo en tiempos de COVID-19. El Mercurio, 10. https://issuu.com/diarioelmercurio/docs/viernes_5_junio_2020

Arias, F. (2012). El proyecto de investigación. Introducción a la metodología científica (6th ed.). Editorial EPISTEME, C.A.

Belkis, R. (2014). Investigación Cualitativa Fundamentos y Praxis. Caracas: FEDEUPEL.

Castañeda, L. (2001). Un plan de vida para jóvenes ¿Qué harás con el resto de tu vida? (J. Núñez (ed.); 1st ed.). Ediciones Poder.

Corbin, J. (1 de diciembre de 2020). Autoconocimiento: definición y ocho consejos para mejorarlo. Psicología y mente. https://psicologiaymente.com/psicologia/autoconocimiento

Cornejo, E. (2015). Elaboración de proyecto de vida basado en valores en estudiantes del Colegio Amoretti. Aportes Metodológicos Filosóficos y Culturales, 13(1), 26-43.

D’angelo, O. (2003). Proyecto de vida y desarrollo integral humano. Revista Internacional Crecemos, 1(6), 31. http://biblioteca.clacso.edu.ar/ar/libros/cuba/cips/caudales05/Caudales/ARTICULOS/ArticulosPDF/07D050.pd $\underline{\mathrm{f}}$

González, A. (2016). Propósito de vida, psicología y salud. INPSI - Instituto de Psiquiatría y Psicoterapia de Madrid.

Hernández, A. (2000). Proyecto de vida como categoría básica de interpretación de la identidad individual y social. Revista Cubana de Psicología, 17 (3), 270-275.

Hernández, R., Fernadez, C., \& Baptista, P. (2014). Metodología de la investigación (6th ed.). Mc Graw Hill Education. http://observatorio.epacartagena.gov.co/wp-content/uploads/2017/08/metodologia-de-la-investigacion-sextaedicion.compressed.pdf

Martinez, M. (1996). Comportamiento Humano Nuevos Métodos de Investigación. Distrito Federal, México: TRILLAS.

Martinez, M. (2004). Ciencia y Arte en la Metodología Cualitativa. México D.F.: TRILLAS.

Maslow, A. (1991). Motivación y personalidad. Madrid, España: Ediciones Díaz de Santos, edición en español.

Morales, F., \& Trueba, I. (2011). Concepto de proyecto: lecciones de experiencia. XV Congreso Internacional de Ingeniería de Proyectos, 337-350. http://oa.upm.es/12747/

Murillo, C. (2014). La construcción de proyectos de vida, como estrategia pedagógica: articulando los contenidos del área de educación religiosa escolar y los subsistemas de la ética compleja (Issue 1) [Universidad San Buenaventura-Seccional Medellín]. https://doi.org/10.1016/j.bbapap.2013.06.007

Parra, D. (2003). Manual de estrategias de enseñanzalaprendizaje (1st ed.). Servicio Nacional de Aprendizaje (SENA).

Paz, M. (2000). Criterios de Validez de la Investigacion Cualtiativa. Revista de Investigación Educativa.

Pimienta, J. (2012). Estrategias de enseñanza-aprendizaje. Docencia universitaria basada en competencias. (1st ed.). Pearson Educación.

Reyes, A. (2016). Modelo Educativo de la Universidad Laica Eloy Alfaro de Manabí (1st ed.). Editorial Mar Abierto.

Salazar, P., Barrera, P., \& Espino, S. (2015). Estado Laico en un país religioso (1st ed., Issue August 2015).

Universidad Nacional Autónoma de México.

Estatuto de la Uninversidad Laica Eloy Alfaro de Manabí, 102 (2019).

Villafuerte, J., Intriago, E., \& Romero, A. (2017). e-Círculo Literario aplicado en la clase de inglés. Una innovación educativa después del terremoto de 2016 en Ecuador. Apertura, 9(2), 54-73.

https://doi.org/10.18381/Ap.v9n2.1013 